\title{
Cyclooxygenase-2 expression is a prognostic biomarker for non-small cell lung cancer patients treated with adjuvant platinum-based chemotherapy
}

\author{
Katsuhiko Shimizu*, Takuro Yukawa, Riki Okita, Shinsuke Saisho, Ai Maeda, Yuji Nojima and Masao Nakata
}

\begin{abstract}
Background: Adjuvant chemotherapy after the resection of stage IB-IIIA non-small cell lung cancer (NSCLC) is now the standard of care based on large-scale phase III trials and a meta-analysis. However, chemotherapy has plateaued in terms of its efficacy, and the search for treatment prediction biomarkers is imperative for the further identification of treatable subgroups. Therefore, we investigated the significance of cyclooxygenase-2 (Cox-2) expression and the applicability of a Cox-2 inhibitor in patients who had received adjuvant chemotherapy.

Methods: We conducted a retrospective review of data from 97 patients who had received adjuvant chemotherapy. The adjuvant chemotherapy consisted of an oral tegafur agent (OT) or platinum-based chemotherapy (PB). The criteria for regimen selection were based on a discussion among the cancer board and enrollment in a clinical trial. Immunohistochemical staining $(\mathrm{IHC})$ for Cox-2 was performed, and the correlation between Cox-2 expression and disease-free survival (DFS) was evaluated.

Results: $I H C$ showed that 56 cases (57.7\%) were positive for Cox-2. The rate of Cox-2 expression was similar for the PB and OT groups. Among the patients who received PB, the DFS of the patients with Cox-2 expression was significantly poorer than that of the patients without Cox-2 expression $(P=0.017)$, but there was no significant difference among the patients who received OT $(P=0.617)$. In a multivariate analysis, Cox-2 expression and lymph node metastasis were independent predictors of DFS among patients who received PB.
\end{abstract}

Conclusions: Cox-2 expression was a powerful predictor of DFS among patients who received PB as an adjuvant chemotherapy. Further study investigating the use of a Cox-2 inhibitor for adjuvant chemotherapy is needed.

Keywords: Non-small cell lung cancer, Adjuvant chemotherapy, Cyclooxygenase-2

\section{Background}

Lung cancer is a leading cause of cancer-related death worldwide. The most effective treatment of early-stage non-small cell lung cancer (NSCLC) is surgical resection. In addition, adjuvant chemotherapy after the resection of stage II-IIIA NSCLC is now the standard of care based on three large-scale phase III trials and an individual patient meta-analysis [1-4]. However, up to $60 \%$ of patients with NSCLC with lymph node metastasis relapse after surgery [5,6]. Currently, chemotherapy has

\footnotetext{
* Correspondence: kshimizu@med.kawasaki-m.ac.jp

Department of General Thoracic Surgery, Kawasaki Medical School, 577 Matsushima, Kurashiki, Okayama 701-0192, Japan
}

plateaued in terms of its efficacy, and the search for treatment prediction biomarkers is imperative for the further identification of treatable subgroups. For unresectable advanced NSCLC, drug selection is usually determined according to histological subtype and gene mutation. The application of these methods to adjuvant treatment is anticipated [7].

Cyclooxygenase (Cox) is the key enzyme required for the conversion of arachidonic acid to prostaglandins (PGs). Two Cox isoforms have been identified and are referred to as constitutive Cox (Cox-1) and inducible Cox (Cox-2); Cox-2 is an inducible enzyme that is activated in response to extracellular stimuli, such as growth 
factors and proinflammatory cytokines [8]. Some investigators have demonstrated that Cox-2 is constitutively overexpressed in a variety of epithelial malignancies, such as lung, breast, pancreas, colon, esophagus, and head and neck cancers, and Cox-2 overexpression is usually associated with a poor prognosis [9-11]. Recently, a clinical trial performed by Cancer and Leukemia Group B demonstrated that Cox-2 expression was a significant prognostic factor among patients with advanced NSCLC receiving chemotherapy [12].

However, to our knowledge, the prognostic impact of Cox-2 expression has not yet been investigated among NSCLC patients who have received adjuvant chemotherapy. In the present study, we investigated the significance of Cox-2 expression among NSCLC patients who have received adjuvant chemotherapy.

\section{Methods}

\section{Study population}

We conducted this retrospective study in a total of 442 patients with NSCLC who underwent resection at the Kawasaki Medical School Hospital between 2004 and 2010. Of these, 97 patients received adjuvant chemotherapy and were enrolled in this study. None of the patients had received either radiotherapy or chemotherapy prior to surgery. The histological diagnosis of the tumors was based on the criteria of the World Health Organization, and the TNM stage was determined according to the 2009 criteria. Informed consent for the study of excised tissue samples from the surgical specimens was obtained from each patient. This study was conducted with the approval of the institutional Ethics Committee of Kawasaki Medical School (No.1417: Approved on March 11, 2013).

\section{Adjuvant chemotherapy and follow-up}

The adjuvant chemotherapy consisted of an oral tegafur agent $(\mathrm{OT})$ or platinum-based chemotherapy (PB). The criteria for regimen selection were based on a discussion among the hospital cancer board and enrollment in a clinical trial. Basically, OT was selected for patients with stage I (T1bNOMO and T2NOM0), and PB was selected for patients with stage II and IIIA $[4,13]$. The OT regimens consisted of tegafur-uracil (UFT) or S1. The PB regimens mainly consisted of carboplatin and paclitaxel, carboplatin and gemcitabine, carboplatin and S1, and other cisplatin regimens. Postoperative radiotherapy was not performed. The schedule for follow-up examinations was arranged on an each individual basis; most of the patients received medical check-ups and chest X-ray films or CT scans at least twice per year. The last follow-up review was performed on June 30, 2014. The median follow-up duration for the determination of disease-free survival (DFS) was 38.6 months (range, 1 to 62 months).

\section{Immunohistochemical staining}

The immunohistochemical analyses were performed using resected, paraffin-embedded lung cancer tissues. After microtome sectioning $(4 \mu \mathrm{m})$, the slides were processed for staining using an automated immunostainer (Nexes; Ventana, Tucson, AZ, USA). The primary antibodies were used according to the manufacturer's instructions (Cox-2: Dako Cytomation, (Glostrup, Denmark) CX-294, 1:50 dilution). The slides were scored for the intensity of staining ( 0 to 3 ) and the percentages of cells with scores of $0(0 \%), 1$ ( $1 \%$ to $9 \%), 2$ ( $10 \%$ to $49 \%$ ), and 3 (50\% to $100 \%)$ were determined. The immunohistochemistry (IHC) score (0 to 9) was defined as the product of the intensity and the percentage of cells. Cox-2 expression was judged as positive when the IHC score was $\geq 4[12]$.

\section{Statistical analysis}

All the statistical analyses were performed using the SPSS statistical package (version 17.0; SPSS, Chicago, IL, USA). Categorical data were examined using the $\chi^{2}$ test. The prognostic evaluation was performed based on DFS. DFS was defined as the time until lung cancer recurrence or non-lung cancer death. The impact of Cox-2 expression on DFS was evaluated according to the type of adjuvant chemotherapy (OT or $\mathrm{PB}$ ). The survival curves were estimated using the Kaplan-Meier method, and differences were evaluated using the log-rank test. Univariate and multivariate analyses were performed using the Cox proportional hazards model. Two-sided $P$ values of less than 0.05 were considered statistically significant.

\section{Results}

\section{Clinical characteristics and chemotherapy regimen}

The patients ranged in age from 46 to 80 years (mean, 66.9 years). There were 63 men and 34 women. The pathological stage and histological type at the time of the final pathological examination are shown in Table 1. The most frequent histological type was adenocarcinoma: 65 patients $(67.0 \%)$ had adenocarcinoma, 17 (17.5\%) had squamous cell carcinoma, 8 (8.2\%) had large cell carcinoma, and 7 (7.3\%) had other subtypes. The patients were classified according to the histopathological stage as follows: 42 patients had stage I, 27 had stage II, and 28 had stage IIIA disease. Of the 97 patients, 51 (52.6\%) received $\mathrm{PB}$, and $46(47.4 \%)$ received OT. The most frequent chemotherapy regimen was carboplatin + paclitaxel in the PB group, and UFT in the OT group. Five cases using carboplatin $+\mathrm{S} 1$ were included in the PB group. 
Table 1 Patient characteristics enrolled in this study $(\mathbf{n}=97)$

\begin{tabular}{|c|c|c|}
\hline & Number & $\%$ \\
\hline \multicolumn{3}{|l|}{$\overline{\text { Sex }}$} \\
\hline Male & 63 & 64.9 \\
\hline Female & 34 & 35.1 \\
\hline Age, mean $\pm S D$ & $66.9 \pm 9.0$ & \\
\hline \multicolumn{3}{|l|}{ Histology } \\
\hline Adenocarcinoma & 65 & 67.0 \\
\hline Squamous cell carcinoma & 17 & 17.5 \\
\hline Large cell carcinoma & 8 & 8.2 \\
\hline Adenosquamous carcinoma & 2 & 2.1 \\
\hline Pleomorphic carcinoma & 5 & 5.2 \\
\hline \multicolumn{3}{|l|}{ Tumor differentiation } \\
\hline Well & 29 & 29.9 \\
\hline Moderate & 29 & 29.9 \\
\hline Poor & 39 & 40.2 \\
\hline \multicolumn{3}{|l|}{ Nodal status } \\
\hline No & 56 & 57.7 \\
\hline N1 & 19 & 19.6 \\
\hline N2 & 22 & 22.7 \\
\hline \multicolumn{3}{|l|}{ Pathological stage } \\
\hline $\mathrm{A}$ & 10 & 10.3 \\
\hline IB & 32 & 33.0 \\
\hline$\|A+\| B$ & 27 & 27.8 \\
\hline$\| I I A$ & 28 & 28.9 \\
\hline \multicolumn{3}{|l|}{ Chemotherapy regimen } \\
\hline Platinum-based agent & 51 & 52.6 \\
\hline CBDCA + paclitaxel & 35 & \\
\hline CBDCA + gemcitabine & 7 & \\
\hline $\mathrm{CBDCA}+\mathrm{S} 1$ & 5 & \\
\hline CDDP + others & 4 & \\
\hline Oral tegafur agent & 46 & 47.4 \\
\hline UFT & 37 & \\
\hline S1 & 9 & \\
\hline
\end{tabular}

SD: standard deviation; CDDP: cisplatin; CBDCA: carboplatin; UFT: tegafur-uracil.

\section{Correlations between chemotherapy regimen and clinicopathological characteristics}

The PB group had a higher proportion of a pathological lymph node status of N1 or N2 than the OT group $(P=0.009)$, but no significant associations were observed between the chemotherapy regimen and patient age $(P=0.248)$, tumor size $(P=0.220)$, or histological subtype $(P=0.897)$ (Table 2$)$.

\section{Cox-2 expression status}

An immunohistochemical study showed that 56 cases (57.7\%) had a positive Cox-2 expression status. The rate of Cox-2 expression in the PB and OT groups were similar (58.8\% vs. $56.5 \%)$ (Table 2 ).

\section{Prognostic analysis}

Among the patients who received OT, the DFS of the patients with Cox-2 expression was not poorer than that of the patients without Cox-2 expression $(P=0.617$, logrank test; Figure 1). On the other hand, among the patients who received $\mathrm{PB}$, the DFS of the patients with Cox-2 expression was significant poorer than that of the patients without Cox-2 expression ( $P=0.017$; Figure 2). In a univariate analysis, Cox-2 expression and lymph node metastasis were predictors of the DFS. Furthermore, in a multivariate analysis, Cox-2 expression $(P=0.011)$, lymph node metastasis $(P=0.030)$, and vascular invasion $(P=0.017)$ were independent predictors of the DFS (Table 3).

\section{Discussion}

Recently, both experimental and clinical studies have revealed that many molecules contribute to the various biological behaviors of malignant tumors including NSCLC. New strategies based on a better understanding of tumor biology are thus needed to maximize the efficacy of current treatments. The associations between these strategies and the response to chemotherapy have been investigated, and the selection of effective chemotherapy regimens based on the evaluation of these biomarkers may improve the clinical outcome of NSCLC patients. PB remains the scaffold upon which combination chemotherapy regimens are assembled for NSCLC patients. As a predictor of the efficacy of $\mathrm{PB}$, the intratumoral expression of excision repair cross-complementing group 1 (ERCC1, a major component of the nucleotide excision repair pathway, is reported to associated with the responsiveness of patients to cisplatin $[14,15]$. In addition, the intratumoral expression of class III $\beta$-tubulin is likely to be associated with the responsiveness to taxanes, such as paclitaxel and docetaxel [16,17]. Moreover, ribonucleotidediphosphate reductase M1 (RPM1) is likely to be associated with the responsiveness to gemcitabine [18]. On the other hand, OT is widely used in Japan [19,20]. 5-Fluorouracil (5-FU)-derived agents, such as UFT and S1, are effective for patients with NSCLC who have a low expression of thymidylate synthase (TS) [21]. However, evidence recommending the routine clinical use of these agents remains insufficient.

In this study, we investigated the prognostic significance of Cox-2 expression among patients with adjuvant chemotherapy. Several studies have suggested a prognostic and predictive role for Cox-2 expression in NSCLC [22-25]. In a 2006 meta-analysis of the role of Cox-2 in NSCLC, a trend toward Cox-2 overexpression as a prognostic factor affecting the survival of patients with 
Table 2 Patient characteristics enrolled in this study $(n=97)$

\begin{tabular}{|c|c|c|c|}
\hline Characteristics & $\begin{array}{l}\text { Platinum-based } \\
\text { Chemotherapy }\end{array}$ & $\begin{array}{l}\text { Oral tegaful } \\
\text { Chemotherapy }\end{array}$ & $P$ value \\
\hline Patients, number & 51 & 46 & \\
\hline Age (mean), year & 65.9 & 68.0 & 0.248 \\
\hline Sex & & & 0.287 \\
\hline Male & 36 & 27 & \\
\hline Female & 15 & 19 & \\
\hline Histology & & & 0.897 \\
\hline Adenocarcinoma & 33 & 32 & \\
\hline Squamous cell carcinoma & 10 & 7 & \\
\hline Large cell carcinoma & 5 & 3 & \\
\hline Adenoaquamous carcinoma & 1 & 1 & \\
\hline Pleomorphic carcinoma & 2 & 3 & \\
\hline Tumor size (mean), mm & 37.7 & 34.3 & 0.220 \\
\hline Pathological nodal status & & & 0.009 \\
\hline pNo & 22 & 34 & \\
\hline $\mathrm{pN} 1$ & 14 & 5 & \\
\hline $\mathrm{pN} 2$ & 15 & 7 & \\
\hline Cyclooxygenase-2 expression & & & 0.819 \\
\hline negative & 21 & 20 & \\
\hline positive & 30 & 26 & \\
\hline
\end{tabular}

NSCLC was observed, but the heterogeneity among the studies was relatively high [26]. In 2008, Edelman et al. reported that Cox-2 expression was a significant prognostic factor in patients with advanced NSCLC (Cancer and Leukemia Group B Trial 30203). Moreover, patients with moderate to high Cox-2 expression had a better tumor response to a Cox-2 inhibitor (celecoxib) in terms of a longer median survival period compared with those not receiving celecoxib [12]. On the other hand, in the NVALT-4 study performed in 2011, Cox-2 expression

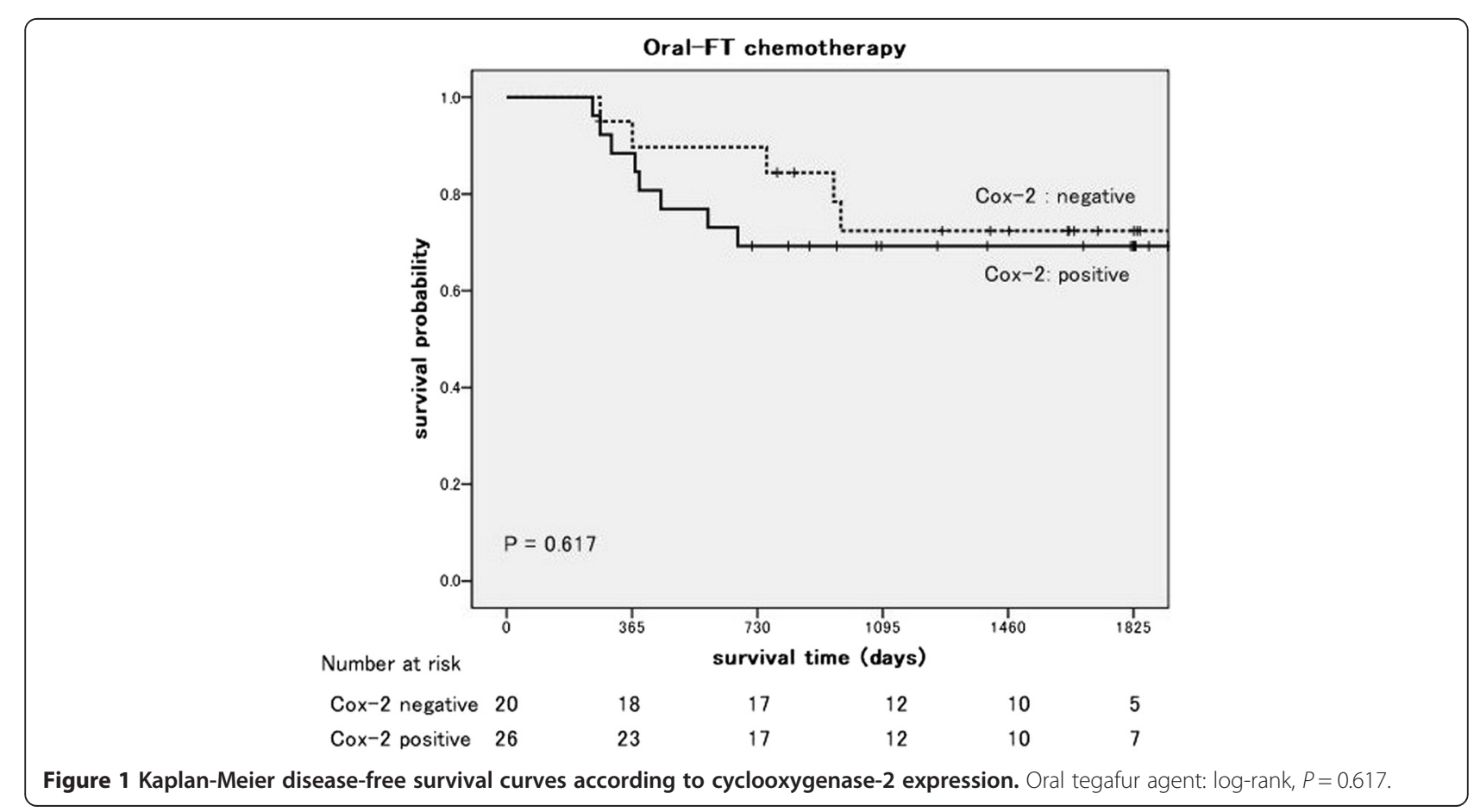




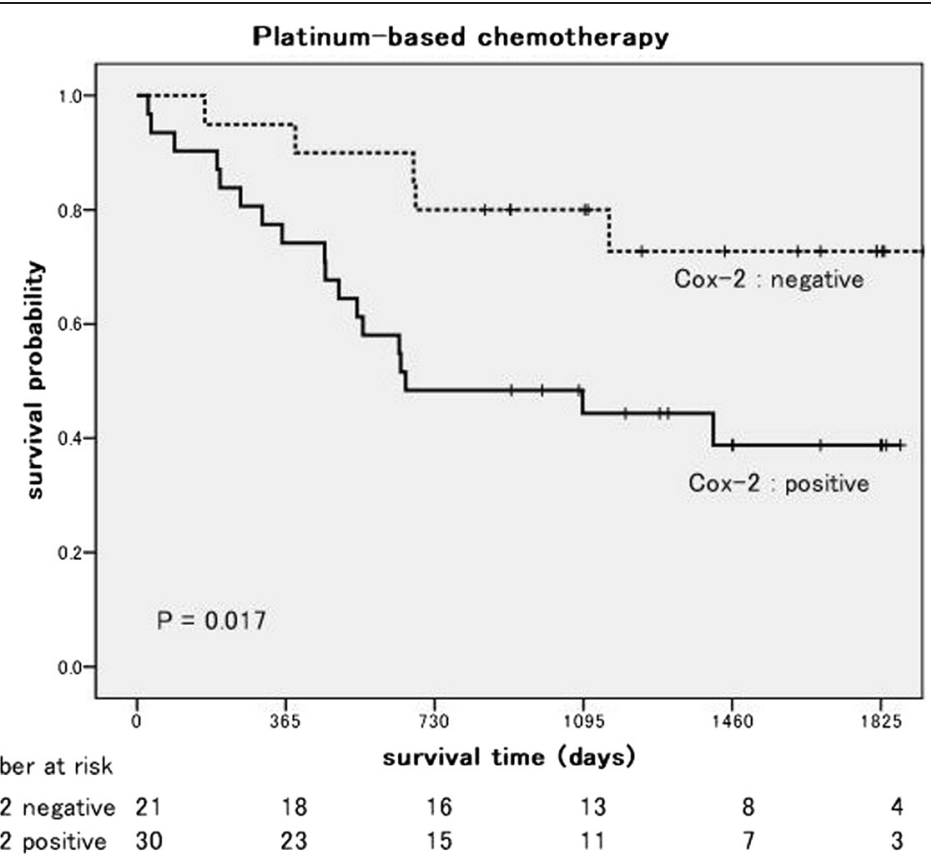

Figure 2 Kaplan-Meier disease-free survival curves according to cyclooxygenase-2 expression. Platinum-based chemotherapy: log-rank, $P=0.017$.

was not a prognostic biomarker and had no predictive value when celecoxib was added to chemotherapy. However, in a subset analysis, patients with squamous cell carcinoma seemed to perform better when treated with celecoxib [27].

The present study focused on patients who had received adjuvant chemotherapy, and we found that Cox-2 expression was a powerful prognostic factor for patients who had received PB. Regarding postoperative chemotherapy, Cox-2 expression was previously reported not to be a significant prognostic factor when using UFT [28]. The results of this previous report were similar to the results of our study on patients who received UFT

Table 3 Multivariate analysis of factors predicting disease-free survival in adjuvant chemotherapy with platinum-based agent

\begin{tabular}{|c|c|c|c|c|c|c|}
\hline & \multicolumn{3}{|c|}{ Univariate } & \multicolumn{3}{|c|}{ Multivariate } \\
\hline & $\mathrm{HR}$ & $95 \% \mathrm{Cl}$ & $P$ value & HR & $95 \% \mathrm{Cl}$ & $P$ value \\
\hline \multicolumn{7}{|l|}{$P$ value } \\
\hline \multicolumn{7}{|l|}{ Gender } \\
\hline Male/female & 1.25 & $0.49-3.18$ & 0.639 & 2.11 & $0.77-5.82$ & 0.149 \\
\hline \multicolumn{7}{|l|}{ Histology } \\
\hline non-SQ/SQ & 1.89 & $0.56-6.37$ & 0.303 & 2.38 & $0.65-8.74$ & 0.191 \\
\hline \multicolumn{7}{|l|}{ Pathological T factor } \\
\hline $\mathrm{T} 3-4 / \mathrm{T} 1-2$ & 1.81 & $0.79-4.13$ & 0.160 & 1.89 & $0.70-5.11$ & 0.208 \\
\hline \multicolumn{7}{|l|}{ Pathological N factor } \\
\hline Positive/negative & 3.63 & $1.34-9.85$ & 0.011 & 3.15 & $1.12-8.85$ & 0.030 \\
\hline \multicolumn{7}{|l|}{ Pleural invasion } \\
\hline $\mathrm{p} 1-3 / \mathrm{p} 0$ & 1.13 & $0.77-1.67$ & 0.533 & 0.82 & $0.50-1.36$ & 0.453 \\
\hline \multicolumn{7}{|l|}{ Vascular invasion } \\
\hline Positive/negative & 2.25 & $0.93-5.52$ & 0.072 & 3.79 & $1.26-11.35$ & 0.017 \\
\hline \multicolumn{7}{|l|}{ Cox-2 expression } \\
\hline Positive/negative & 3.14 & $1.16-8.49$ & 0.024 & 3.96 & $1.38-11.38$ & 0.011 \\
\hline
\end{tabular}

$P$ value was calculated by log-rank test. HR: hazard ratio; $95 \% \mathrm{Cl}$ : 95\% confidence interval; SQ: squamous cell carcinoma; Cox-2: cyclooxygenase-2. 
or S1. However, whether Cox-2 expression is a significant prognostic factor when postoperative $\mathrm{PB}$ is used has been previously reported. The reason for the difference in the effects observed in the $\mathrm{PB}$ and OT groups remains unclear. Of interest, the results from a preclinical analysis showed that a Cox-2 inhibitor enhanced the responses to chemotherapy with cisplatin or paclitaxel through the existence of a functional p53-Cox-2 connection in response to DNA damage [29]. From these preclinical findings and the present reported study, the combination of $\mathrm{PB}$, but not OT, and a Cox- 2 inhibitor could be promising. Based on these observations and the present study, we propose that a clinical trial examining the use of a Cox-2 inhibitor in platinum-based adjuvant chemotherapy should be conducted.

This study had several limitations that should be considered when interpreting the results. The retrospective study design and the relatively small number of enrolled patients were the major limitations of the present study.

\section{Conclusions}

In conclusion, the present study suggests that Cox-2 expression was a powerful predictor of DFS among patients who received $\mathrm{PB}$ as an adjuvant chemotherapy. Further study investigating the use of a Cox-2 inhibitor for adjuvant chemotherapy is needed.

\section{Abbreviations}

5-FU: 5-fluorouracil; Cox: cyclooxygenase; Cox-1: constitutive Cox; Cox-2: inducible Cox; DFS: disease-free survival; ERCC1: excision repair cross-complementing group 1; IHC: immunohistochemistry; NSCLC: non-small cell lung cancer; OT: oral tegafur agent; PB: platinum-based chemotherapy; PGs: prostaglandins; RPM1: ribonucleotide-diphosphate reductase M1; TS: thymidylate synthase; UFT: tegafur-uracil.

\section{Competing interests}

The authors declare that they have no competing interests.

\section{Authors' contributions}

KS, MN contributed to the study concept and design. RO, SS and YN contributed to data acquisition. TY and AM performed the immunohistochemistry. $\mathrm{KS}$ and RO contributed to data analysis and interpretation. KS prepared the manuscript. MN reviewed the manuscript. All the authors have read and approved the final manuscript.

\section{Acknowledgements}

This work was supported in part by a Research Project Grant (NO.24-32) from Kawasaki Medical School. The authors thank Keiko Isoda for providing technical assistance.

Received: 19 August 2014 Accepted: 23 December 2014

Published online: 06 February 2015

\section{References}

1. Arriagada R, Bergman B, Dunant A, Le Chevalier T, Pignon JP, Vansteenkiste J. Cisplatin-based adjuvant chemotherapy in patients with completely resected non-small-cell lung cancer. N Engl J Med. 2004;350:351-60.

2. Winton $T$, Livingston $R$, Johnson $D$, Rigas J, Johnston $M$, Butts $C$, et al. Vinorelbine plus cisplatin vs. observation in resected non-small-cell lung cancer. N Engl J Med. 2005:352:2589-97.

3. Douillard JY, Rosell R, De Lena M, Carpagnano F, Ramlau R, Gonzáles-Larriba $\mathrm{J}$, et al. Adjuvant vinorelbine plus cisplatin versus observation in patients with completely resected stage IB-IIIA non-small-cell lung cancer (Adjuvant
Navelbine International Trialist Association [ANITA]): a randomised controlled trial. Lancet Oncol. 2006;7:719-27.

4. Pignon JP, Tribodet H, Scagliotti GV, Douillard JY, Shepherd FA, Stephens RJ, et al. Lung adjuvant cisplatin evaluation: a pooled analysis by the LACE collaborative group. J Clin Oncol. 2008;26:3552-9.

5. Asamura H, Goya T, Koshiishi Y, Sohara Y, Eguchi K, Mori M, et al. A Japanese lung cancer registry study: prognosis of 13,010 resected lung cancers. J Thorac Oncol. 2008;3:46-52.

6. Asamura $\mathrm{H}$, Nakayama $\mathrm{H}$, Kondo $\mathrm{H}$, Tsuchiya R, Naruke T. Lobe-specific extent of systematic lymph node dissection for non-small cell lung carcinomas according to a retrospective study of metastasis and prognosis. J Thorac Cardiovasc Surg. 1999;117:1102-11.

7. Mitsudomi T, Suda K, Yatabe Y. Surgery for NSCLC in the era of personalized medicine. Nat Rev. 2013;10:235-44.

8. Dubois RN, Abramson SB, Crofford L, Gupta RA, Simon LS, Van De Putte LB, et al. Cyclooxygenase in biology and disease. FASEB J. 1998;12:1063-73.

9. Hida T, Yatabe $Y$, Achiwa H, Muramatsu H, Kozaki K, Nakamura S, et al. Increased expression of cyclooxygenase 2 occurs frequently in human lung cancers, specifically in adenocarcinomas. Cancer Res. 1998;58:3761-4.

10. Hwang D, Scollard D, Byrne J, Levine E. Expression of cyclooxygenase-1 and cyclooxygenase-2 in human breast cancer. J Natl Cancer Inst. 1998;90:455-60.

11. Ogino S, Kirkner GJ, Nosho K, Irahara N, Kure S, Shima K, et al. Cyclooxygenase-2 expression is an independent predictor of poor prognosis in colon cancer. Clin Cancer Res. 2008;14:8221-7.

12. Edelman MJ, Watson D, Wang X, Morrison C, Kratzke RA, Jewell S, et al. Eicosanoid modulation in advanced lung cancer: cyclooxygenase-2 expression is a positive predictive factor for celecoxib + chemotherapy - Cancer and Leukemia Group B Trial 30203. J Clin Oncol. 2008;26:848-55.

13. Hamada C, Tsuboi M, Ohta M, Fujimura S, Kodama K, Imaizumi M, et al. Effect of postoperative adjuvant chemotherapy with tegafur-uracil on survival in patients with stage IA non-small cell lung cancer: an exploratory analysis from a metaanalysis of six randomized controlled trials. J Thorac Oncol. 2009:4:1511-6.

14. Lord RV, Brabender J, Gandara D, Alberola V, Camps C, Domine M, et al. Low ERCC1 expression correlates with prolonged survival after cisplatin plus gemcitabine chemotherapy in non-small cell lung cancer. Clin Cancer Res. 2002;8:2286-91.

15. Olaussen KA, Dunant A, Fouret $P$, Brambilla E, André F, Haddad V, et al. DNA repair by ERCC1 in non-small cell lung cancer and cisplatin-based adjuvant chemotherapy. N Engl J Med. 2006;355:983-91.

16. Seve P, Mackey J, Isaac S, Tredan O, Souquet PJ, Perol M, et al. Class III $\beta$ tubulin expression in tumor cells predicts response and outcome in patients with non-small cell lung cancer receiving paclitaxel. Mol Cancer Ther. 2005:4:2001-7

17. Reiman T, Lai R, Veillard AS, Paris E, Soria JC, Rosell R, et al. Cross-validation study of class III beta-tubulin as a predictive marker for benefit from adjuvant chemotherapy in resected non-small-cell lung cancer: analysis of four randomized trials. Ann Oncol. 2012;23:86-93.

18. Bepler G, Williams C, Schell MJ, Chen W, Zheng Z, Simon G, et al. Randomized international phase III trial of ERCC1 and RRM1 expression-based chemotherapy versus gemcitabine/carboplatin in advanced non-small-cell lung cancer. J Clin Oncol. 2013;31:2404-12.

19. Kato H, Ichinose $\mathrm{Y}$, Ohta M, Hata E, Tsubota $N$, Tada H, et al. A randomized trial of adjuvant chemotherapy with uracil-tegafur for adenocarcinoma of the lung. N Engl J Med. 2004;350:1713-21.

20. Okamoto I, Yoshioka H, Morita S, Ando M, Takeda K, Seto T, et al. Phase III trial comparing oral S-1 plus carboplatin with paclitaxel plus carboplatin in chemotherapy-naïve patients with advanced non-small-cell lung cancer: results of a west Japan oncology group study. J Clin Oncol. 2010;28:5240-6.

21. Nakano J, Huang C, Liu D, Masuya D, Nakashima T, Yokomise H, et al. Evaluations of biomarkers associated with 5-FU sensitivity for non-small cell lung cancer patients postoperatively treated with UFT. Br J Cancer. 2006;95:607-15.

22. Masferrer JL, Leahy KM, Koki AT, Zweifel BS, Settle SL, Woerner BM, et al. Antiangiogenic and antitumor activities of cyclooxygenase-2 inhibitors. Cancer Res. 2000;60:1306-11.

23. Brabender J, Park J, Metzger R, Schneider PM, Lord RV, Hölscher AH, et al. Prognostic significance of cyclooxygenase 2 mRNA expression in non-small cell lung cancer. Ann Surg. 2002;235:440-3.

24. Khuri FR, Wu H, Lee JJ, Kemp BL, Lotan R, Lippman SM, et al. Cyclooxygenase-2 overexpression is a marker of poor prognosis in stage I non-small cell lung cancer. Clin Cancer Res. 2001;7:861-7. 
25. Altorki NK, Keresztes RS, Port JL, Libby DM, Korst RJ, Flieder DB, et al. Celecoxib, a selective cyclo-oxygenase-2 inhibitor, enhances the response to preoperative paclitaxel and carboplatin in early-stage non-small-cell lung cancer. J Clin Oncol. 2003;21:2645-50.

26. Mascaux C, Martin B, Paesmans M, Berghmans T, Dusart M, Haller A, et al. Has Cox-2 a prognostic role in non-small-cell lung cancer? A systematic review of the literature with meta-analysis of the survival results. $\mathrm{Br} J$ Cancer. 2006;95:139-45

27. Groen HJ, Sietsma H, Vincent A, Hochstenbag MM, van Putten JW, van den Berg A, et al. Randomized, placebo-controlled phase III study of docetaxel plus carboplatin with celecoxib and cyclooxygenase-2 expression as a biomarker for patients with advanced non-small-cell lung cancer: the NVALT-4 study. J Clin Oncol. 2011;29:4320-6.

28. Tanaka F, Takenaka K, Yanagihara K, Fukushima M, Wada H. COX-2 status is significant factor to predict a postoperative survival as well as an efficacy of postoperative adjuvant therapy in non-small cell lung cancer. J Clin Oncol. 2004;22:9556.

29. Duarte ML, de Moraes E, Pontes E, Schluckebier L, de Moraes IL, Hainaut P, et al. Role of p53 in the induction of cyclooxygenase-2 by cisplatin or paclitaxel in non-small cell lung cancer cell lines. Cancer Lett. 2009;28:57-64.

\section{Submit your next manuscript to BioMed Central and take full advantage of:}

- Convenient online submission

- Thorough peer review

- No space constraints or color figure charges

- Immediate publication on acceptance

- Inclusion in PubMed, CAS, Scopus and Google Scholar

- Research which is freely available for redistribution 